\title{
サツマイモ品種‘すいおう’の茎葉生産に適する養液栽培方式
}

\author{
江口壽彦 $^{1} \cdot$ 森山修志 $^{2} \cdot$ 宮島郁夫 $^{3} \cdot$ 吉田 敏 $^{1} \cdot$ 筑紫二郎 ${ }^{1}$ \\ ${ }^{1}$ 九州大学生物環境調節センター $812-8581$ 福岡市東区箱崎 6-10-1 \\ ${ }^{2} \mathrm{JA}$ 全農扮おいた 870-0844 大分市古国府 1220 \\ 3 九州大学熱帯農学研究センター 812-8581 福岡市東区箱崎 6-10-1
}

\section{A Hydroponic Method Suitable for Tops Production of a Sweetpotato Cultivar 'Suioh'}

\author{
Toshihiko EGUCHI ${ }^{1}$, Shuji MoriYama ${ }^{2}$, Ikuo MiYaJIMA ${ }^{3}$, Satoshi YoshidA ${ }^{1}$ and Jiro CHIKUSHI ${ }^{1}$ \\ ${ }^{1}$ Biotron Institute, Kyushu University, Fukuoka, 812-8581 \\ ${ }^{2} J A-Z E N-N O H$ Oita, Furugoh, Oita, Oita, 870-0844 \\ ${ }^{3}$ Institute of Tropical Agriculture, Kyushu University, Fukuoka, 812-8581
}

\begin{abstract}
'Suioh' is a sweetpotato (Ipomoea batatas (L.) Lam.) cultivar developed for utilizing the tops as a green vegetable The leaves are rich in lutein and polyphenol, which increases the economic value of the cultivar as a functional food. An hydroponic method suitable for tops production from 'Suioh' was examined by comparing a deep flow technique (DFT) system with a pumice sand culture (PSC) system in the phytotron glass room of the Biotron Institute of Kyushu University located in Fukuoka city, Japan. The air temperature and humidity of the room were controlled at $25^{\circ} \mathrm{C}$ and $70 \% \mathrm{RH}$, respectively. In early summer, the DFT system showed 2 times higher yield than the PSC system, while the lutein concentration in the leaves in DFT-grown plants was 30\% lower than that of those grown in the PSC system In winter, the yield in DFT was 1.2 times higher than that in the PSC system, and both lutein and polyphenol concentrations were almost the same between these two hydroponic systems. Thus, the DFT system is considered appropriate for 'Suioh' production, although it requires the development of a cultivation technique to increase the lutein concentration in leaves. The effects of cultural conditions on the concentrations of functional food factors were also investigated. Concentration of the nutrient solution scarcely affected the concentrations of lutein and polyphenol in the leaves, whereas increased light intensity appeared to increase both the lutein and polyphenol concentrations.
\end{abstract}

Key words: functional food, green vegetable, hydroponics, sweetpotato

\section{緒言 \\ サツマイモ (Ipomoea batatas (L.) Lam.) 品種“すいお う’は葉と葉柄を食用とする茎葉利用型の品種である. ‘す}

2007 年 4 月 17 日受付

2007 年 7 月 18 日受理

Corresponding author: Toshihiko Eguchi (egut@ agr.kyushu-u.ac.jp)
いおう’は, 従来の茥葉利用品種に比べて葉の食味が良好 で, 収量も優れていることから新規野菜として有望視されて いる ${ }^{7)}$. また, 他の野菜と比較すると, 葉には機能性成分で あるルテインとポリフェノールが非常に高い濃度で含まれてい る $^{7,8)}$. ルテインの摂取は眼の機能強化や眼病予防に有効と されており ${ }^{14)}$, またサツマイモ葉のポリフェノールは抗酸化能, 抗炎症作用, 抗がん作用, 抗 HIV 活性, 抗高血圧作用, 抗 糖尿病作用を有することが示されている ${ }^{18)}$.このことから, “す いおう’の葉は経済的価值がより高い「機能性食品」として 
も期待されており, 本品種は生鮮野菜としてのほか, 加工食 品や医薬品の原料としても利用することができる.

‘すい挹う”葉菜として利用するには, 周年安定供給によ り市場性を高めることが求められるが, サツマイモは熱帯・亜 熱带起源の作物であるため生育に高温が必要であり, 本邦 九州以北に抢ける冬季低温期には加温八ウスなどの施設内 で栽培されることとなる. また, 収量や品質を安定させるという 観点から養液栽培による生産技術の確立が望ましい.しかし, サツマイモは通常露地戋場で塊根収量を上げることを前提に 栽培体系が確立されており，茎葉部の集約的生産を試みた 報告はない. したがって, ‘すい抄う’を市場に周年安定供給 するには, あらためて茎葉生産のための養液栽培を体系化す ることが必要である.

以上の観点から, 本研究では, ‘すいおう’ の生産体系確 立の一助として, まず養液栽培方式の検討を行なった. 養液 栽培は固形培地の有無により固形培地耕と水耕に大別され ており,これら 2 種の方式で栽培した ‘すいおう’ の収量と品 質の差異を比較調查した. ここでは, ‘すいおう’ に特徴的に 多く含まれるとされるルテインとポリフェノールの含量を品質の 指標とした. また, 他の作物に打いて, 葉のルテイン含量やポ リフェノール含量に養分供給や光条件が影響することが報告 されている ${ }^{1-4,11,12,15,17)}$ ，そこで, 培養液濃度あるいは光強度 がこれら機能性成分の含量に影響を及ぼす可能性について も検証した。

\section{材料および方法}

植物材料の育成および生育実験は, すべて九州大学生物 環境調節センターのファイトトロンガラス室および人工照明グロ ースチャンバで行なった.

\section{1.植物材料}

気温 $25^{\circ} \mathrm{C}$, 相対湿度 $70 \%$ のファイトロンガラス室で生育さ せたサツマイモ品種 ‘すいおう’を材料として用いた. 実験に は, 3 葉を有する扱し穂をバーミキュライトに垂直に扱し, 同室 に7日間置いて発根させたものを用いた。

\section{2.養液栽培装置}

水耕には湛液式水耕を, 固形培地耕にはパミスサンド耕を 採用した。湛液式水耕装置は循環式とし, 水耕ベッド (栽培 槽 $1050 \mathrm{~mm} \mathrm{~L} \times 300 \mathrm{~mm} \mathrm{~W} \times 50 \mathrm{~mm} \mathrm{D}$, 容量 $15 l$ l) と培養

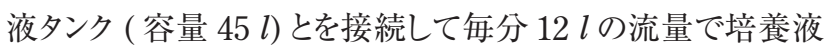
を循環させた。 なお，培養液タンクには冷却パイプ $(\mathrm{EC}-10$, EYELA) と水温調節器 (NTT-2200, EYELA) を設置してお り, 培養液温の粗調節も可能である. 固形培地耕には湛液 式水耕装置と同サイズのベッドを用い, ビニールシートを敷い て, パミスサンド (パミス, 大江化学工業)を充填した。 パミ
スサンドは多孔質火成岩を母材とする白色の固形培地で, 本研究では粒径 $2.4 \sim 4 \mathrm{~mm}$ に調整したものを用いた. パ ミスサンド耕での植物への培養液供給には, 自動灌水装置 (EY4200-H, National) を用い, 午前 8 時と午後 3 時にそれ ぞれ 1 個体当たり $600 \mathrm{ml}$ を給液し，掛け捨てとした，両栽培 装置を気温 $25^{\circ} \mathrm{C}$, 相対湿度 $70 \%$ のアイトトロンガラス室に設 置した.

\section{3.パミスサンド耕と湛液式水耕との比較}

3 葉を有する発根苗を両養液栽培装置に 5 個体ずつ移植 し. 夏作として 2006 年 5 月 18 日〜 6 月 1 日 (14 日間), 冬 作として 2006 年 12 月 22 日〜 2007 年 1 月 12 日 (21日間 ) に栽培実験を行なった。 なお, 一般栽培を想定して培養液 温は無制御とした. 冬作の実験期間が長いのは, 冬期の植 物生育が夏作に比べて不良であったことによる. 培養液には 大塚八ウス 1 号, 2 号 (大塚化学) の $1 / 2$ 処方を用いた. 培養液の電気伝導度 $(\mathrm{EC})$ は $1.2 \mathrm{mS} \mathrm{cm}^{-1}$ で, $\mathrm{pH}$ は 5.0 5.5 の範囲内になるように水酸化ナリリウム溶液で調整した. ま た，実験期間中の両方式での地下部の温度環境を調べるた めに, ベッドの中心部の深さ $5 \mathrm{~cm}$ の位置に $\mathrm{T}$ - 熱電対を挿入 し, 培地温および培養液温を測定した. 温度測定位置は, ベッドに栽植した植物体の茎部下端の位置に相当する.

栽培期間終了後, 可食部収量として葉身重と葉柄重を調 査し, また地上部生育の指標として, 葉数, 葉面積, 主茥 長, 側枝数および側枝長を調査した. 葉面積については, 主 茎先端から第 $3 \sim 8$ 葉の面積を葉面積計 (AAM-9 型, 林 電工 ) で測定した。側枝長は, 展開葉を有する側枝すべて の茎長を測定し, 1 個体の全側枝の総計として求めた. 葉面 積の計測に用いた葉抢よび葉柄をそれぞれ凍結乾燥粉末に し,ルテインおよび総ポリフェノール含量の測定に用いた。

ルテインの定量は満田ら ${ }^{13)}$ の方法に準じた. アセトンで抽 出した試料液を高速クロマトグラフイシステム (ポンプ : LC10AD, カラム:CTO-10A, 検出器: SPD-10AV, 島津製作所) で定量した. 直線グラジエント法により, 移動相 A 液 (アセ卜 ニトリル：水 $(9: 1))$ を初期条件とし, 直線的にB 液 (酶酸 エチル ) 濃度を上げ 20 分後に $\mathrm{A}: \mathrm{B}=50: 50$ とし, 流速 1.5 $\mathrm{m} l \mathrm{~min}^{-1}$ で溶出を行なった. 測定波長は $450 \mathrm{~nm}$ とした.

総ポリフェノール含量は, フォーリンチオカルト法で測定した. 凍結乾燥試料 $50 \mathrm{mg}$ に $80 \%$ エタノール $5 \mathrm{ml}$ を添加し, 100 ${ }^{\circ} \mathrm{C}$ で 5 分間加熱した後に $4000 \mathrm{rpm}$ で 10 分間遠心分離し, 上澄液を濾過して抽出液を採取した. 残查に $80 \%$ エ夕ノール $5 \mathrm{ml}$ を加え, 再度加熱, 遠心分離および滤過により抽出を行 なった. 再抽出作業は計 3 回行なった. 得られた上澄液を合 わせ, $80 \%$ エタールを加えて $25 \mathrm{ml}$ とした. $1 \mathrm{ml}$ の抽出液に 蒸留水を加えて $10 \mathrm{ml}$ とし, これに $2 \mathrm{ml}$ のフォーリンチオカル トフェノール試薬 (Sigma 製)を加えてよく擋拌し, 5 分後に 
$2 \mathrm{ml}$ の炭酸ナトリウム飽和溶液を加えよく摚拌した. 1 時間後 に吸光光度計 (UV mini-1240, SHIMADZU) を用いて 640 $\mathrm{nm}$ での吸光度を測定した. 既知の濃度のクロロゲン酸溶液 で得られた検量線から抽出物の総ポリフェノール含量をクロロ ゲン酸当量として得た。

\section{4. 栽培条件が品質に及ぼす影響}

培養液濃度および光強度が ‘すいおう’ の機能性食品とし ての品質に及ぼす影響を調査した. 本実験では静置式の湛 液式水耕を採用し, 5 千分の $1 \mathrm{a}$ ワグネルポットに $3 l$ の培養液 を満たし，観賞魚用エアポンプ (CHIKARA $\alpha-4000 S W$, ニッ ソー ) で通気した。 ワグネルポットに発根苗を移植し, 気温 25 ${ }^{\circ} \mathrm{C}$, 相対湿度 $70 \%, 12$ 時間日長のグロースチャンバで 14 日 間栽培した. 光源には白色蛍光灯 (FLR40SW/M, 東芝ライ テック ) 44 本と白熱灯 (TAI220V100WE，東芝ライテック ) 8 個を用いた. 培養液濃度の影響調査では, 大塚ハウス 1 号, 2 号の $1 / 2$ 処方を対照区とし, 標準処方を 2 倍濃度区とし, 光強度 (PPFD) $200 \mu \mathrm{mol} \mathrm{m}^{-2} \mathrm{~s}^{-1}$ で生育させた. $\mathrm{EC}$ は対 照区で $1.2 \mathrm{mS} \mathrm{cm}^{-1}, 2$ 倍濃度区で $2.4 \mathrm{mS} \mathrm{cm}^{-1}$ であった. $\mathrm{pH}$ は 5.0 ～ 5.5 の範囲内に調整した. 各区に 4 個体ずつ供 試した. 光強度の影響調査では, 光強度 (PPFD) $200 \mu \mathrm{mol}$ $\mathrm{m}^{-2} \mathrm{~s}^{-1}$ を対照区とし, またワグネルポットの位置を光源に近づ

2006/May/21 (clear weather)

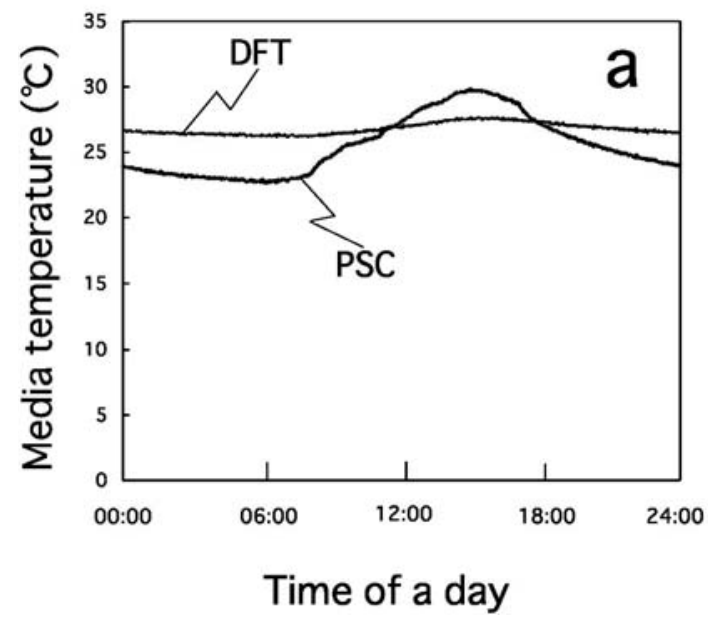

けることで，相対的に強光となる条件 $\left(280 \mu \mathrm{mol} \mathrm{m}{ }^{-2} \mathrm{~s}^{-1}\right)$ を創 出してこれを強光区とした. なお, 別途調查した両区間の葉 温差 (3 個体の平均值 ) は明期中で $0.7^{\circ} \mathrm{C}$, 全日で $0.5^{\circ} \mathrm{C}$ であ り, 実験結果にこの温度差が大きく影響した可能性は小さい と考えられる. 培養液には大塚八ウス 1 号, 2 号の $1 / 2$ 処方 を用いた，各区に 4 個体ずつ供試した．両実験とも，収量と して葉身重を, 品質としてルテインおよびポリフェノールの含量 を調査した. なお，グロースチャンバに移植する前に葉が受け た前歴が実験結果に影響するのを避けるために, 移植後に 展開した葉についてのみ収量と品質の評価を行なった。

\section{結果および考察}

\section{1. 養液栽培方式の検討}

\section{(1)養液栽培方式による培地温の違い}

栽培期間中の培地温には, 両方式に差異が認められた. 夏作での晴天日と曇天日のパミスサンド耕および湛液式水耕 での培地温の日変化を Fig. 1 に例示する. パミスサンド耕で は，晴天日には，日中に培地温が大きく上昇した (Fig. 1a)。曇 天日には, 両方式とも培地温はほぼ一定で, パミスサンド耕で は湛液式水耕よりも低い值で推移した (Fig. 1b). 夏作および

\section{6/May/19(cloudy weather)}

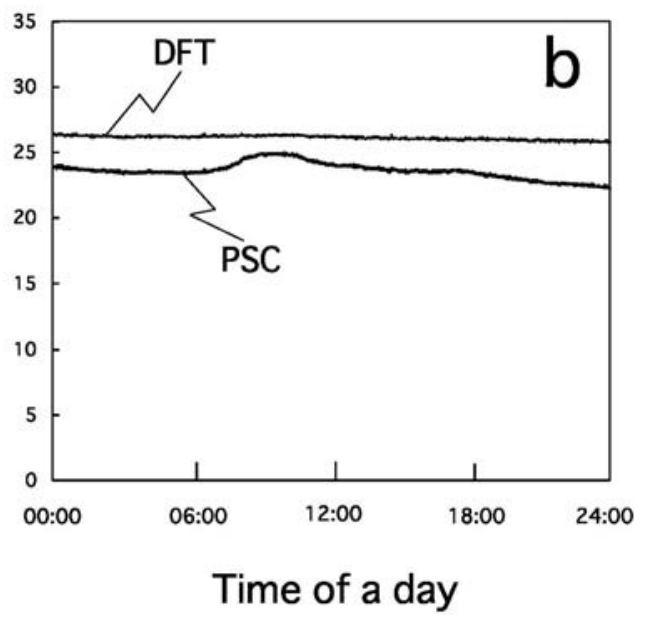

Fig. 1 Time course of root media temperature on a clear day (a) and a cloudy day (b) in the pumice sand culture (PSC) system and the deep flow technique (DFT) system. Both of hydroponic systems were placed in the phytotron glass room controlled at an air temperature of $25^{\circ} \mathrm{C}$ and a relative humidity of $70 \%$.

Table 1 Root media temperatures in the pumice sand culture (PSC) system and the deep flow technique (DFT) system.

\begin{tabular}{lcccc}
\hline \hline \multicolumn{1}{c}{ Date } & $\begin{array}{c}\text { Cultivation } \\
\text { system }\end{array}$ & Average & Maximum & Minimum \\
\hline \multirow{2}{*}{ 2006/May/1-Jun/01 } & PSC & $24.6^{\circ} \mathrm{C}$ & $31.2^{\circ} \mathrm{C}$ & $22.2^{\circ} \mathrm{C}$ \\
& DFT & $26.5^{\circ} \mathrm{C}$ & $27.9^{\circ} \mathrm{C}$ & $25.8^{\circ} \mathrm{C}$ \\
$2006 / \mathrm{Dec} / 22-2007 / \mathrm{Jan} / 12$ & PSC & $23.0^{\circ} \mathrm{C}$ & $29.2^{\circ} \mathrm{C}$ & $21.3^{\circ} \mathrm{C}$ \\
& DFT & $26.4^{\circ} \mathrm{C}$ & $27.7^{\circ} \mathrm{C}$ & $25.7^{\circ} \mathrm{C}$ \\
\hline
\end{tabular}


冬作での培地温の平均值, 最高值, および最低值を Table 1 に示す. 夏作栽培実験期間中の培地温の変動幅は, パミス サンドで約 $9^{\circ} \mathrm{C}$, 湛液式水耕で約 $2^{\circ} \mathrm{C}$ であり, 平均值はパミス サンド耕が湛液式水耕よりも約 $2^{\circ} \mathrm{C}$ 低かった. また, 冬作にお いては, パミスサンド耕での変動幅は約 $8^{\circ} \mathrm{C}$, 湛液式水耕で は約 $2^{\circ} \mathrm{C}$ であり, 培地温の平均值はパミスサンド耕が湛液式 水耕よりも約 $3^{\circ} \mathrm{C}$ 低かった. このように, 同じ気温条件下にあっ ても両栽培方式間には平均で $2 \sim 3{ }^{\circ} \mathrm{C}$ 培地温の違いがあ り, パミスサンド耕では日射によって培地温が大きく変動した. 湛液式水耕では日射による培地温の変動が少なく, 室温よりも やや高い值で推移していた。 これら 2 種の養液栽培方式で は, このように地下部の温度に大きな違いが生じることが示唆 された。

\section{(2)夏作での比較}

地域気象観測所福岡地点 (福岡県福岡市中央区大濠) のデータによると, 夏作の実験期間中 (2006 年 5 月 18 日〜 6 月 1 日)の日照時間の累計は 83.7 時間, 全天日射量の累計 は $255.5 \mathrm{MJ} \mathrm{m}^{-2}$ であった. Table 2 に夏作での各栽培方式 における可食部収量, 葉数, 葉面積, 主茎長, 側枝長, およ び側枝数を示す. 湛液式水耕では, 葉身および葉柄ともパミ スサンド耕の約 2 倍の収量が得られ，5\%水準で有意差が認 められた. 葉数, 葉面積, 主茥長, 側枝長, および側枝数の 全てにおいて湛液式水耕が $5 \%$ 水準で有意に高い值を示し た.これは, 湛液式水耕においては, 葉の展開, 葉面積の拡 大, 主茥の伸長, 分枝がより盛んであったことを示す.このよう に, 湛液式水耕では地上部の生育が旺盛で, パミスサンド耕

\section{よりも顕著に高い収量をもたらした。}

機能性成分であるルテインおよびポリフェノールの含量を Table 3 に示す.ルテインおよびポリフェノールともに, 栽培方 式に関わらず葉柄での含量は葉身よりも著しく低く, また栽培 方式間にも有意な差は認められなかった. 葉身のルテイン含 量は, 湛液式水耕での值がパミスサンド耕での值よりも約 30 \%少なく, $5 \%$ 水準の有意差が認められた. 一方, 葉身の総ポ リフェノール含量には栽培方式間に有意な差は認められなか つた. Ishiguro and Yoshimoto ${ }^{8)}$ が報告した露地栽培の “す いおう’ のルテイン含量は $36.8 \mathrm{mg} \cdot 100 \mathrm{~g}^{-1} \mathrm{FW}$ であり, 本 実験のパミスサンド耕での值 $6.84 \mathrm{mg} \cdot 100 \mathrm{~g}^{-1} \mathrm{FW}$ は, その 6 分の 1 であった. ルテインの定量は, 本研究と同様に満田 $ら^{13)}$ の方法に準じている. 圃場での露地栽培と制御温室で の養液栽培とでは地上部の環境も地下部の環境も大きく異な ることから, このルテイン含量の違いがいかなる栽培条件に起 因するのかについて検討を要する.

夏作での両栽培方式の比較においては, 特に収量に大き な違いが認められた. 栽培方式間には平均で約 $2^{\circ} \mathrm{C} の$ 地温 の違いがあり (Table 1), これが地上部生育に影響を及ぼし た可能性がある. そこで, 2006 年 9 月 28 日から 10 月 12 日 までの 14 日間に, 湛液式水耕装置の培養液温を低く調節す ることで培地温の違いを小さくした条件下で両方式の比較実 験を再度行ない, 収量および品質を調査した。 地域気象観 測所福岡地点での日照時間の累計は 102 時間, 全天日射量 の累計は $229.8 \mathrm{MJ} \mathrm{m}^{-2}$ で, 夏作よりも日照時間は長かった が, 日射量は約 10\%少なかった. 栽培期間中の平均の培地

Table 2 Yields, number of leaves, leaf area, main stem length, number of lateral stems, and sum of lateral stem length of 'Suioh' grown in the PSC system and the DFT system from May 18 to June 1, 2006.

\begin{tabular}{|c|c|c|c|c|c|c|c|}
\hline \multirow{2}{*}{$\begin{array}{c}\text { Cultivation } \\
\text { system }\end{array}$} & \multicolumn{2}{|c|}{$\begin{array}{c}\text { Yields } \\
\left(\text { g plant }^{-1}\right)\end{array}$} & \multirow{2}{*}{$\begin{array}{c}\text { No. of leaves } \\
\text { per plant }\end{array}$} & \multirow{2}{*}{$\begin{array}{l}\text { Leaf area } \\
\left(\mathrm{cm}^{2} \text { leaf }^{-1}\right)\end{array}$} & \multirow{2}{*}{$\begin{array}{l}\text { Main stem } \\
\text { length }(\mathrm{cm})\end{array}$} & \multirow{2}{*}{$\begin{array}{c}\text { No. of } \\
\text { lateral stems } \\
\text { per plant }\end{array}$} & \multirow{2}{*}{$\begin{array}{c}\text { Sum of } \\
\text { lateral stem } \\
\text { length }(\mathrm{cm})\end{array}$} \\
\hline & Leaf & Petiole & & & & & \\
\hline PSC & $27.8 \pm 3.3$ & $19.2 \pm 2.1$ & $18.6 \pm 1.1$ & $109.5 \pm 5.5$ & $33.8 \pm 2.1$ & $4.4 \pm 0.7$ & $11.4 \pm 3.2$ \\
\hline DFT & $57.4 \pm 2.1$ & $40.2 \pm 2.2$ & $33.2 \pm 2.0$ & $136.4 \pm 6.7$ & $46.4 \pm 2.4$ & $9.2 \pm 0.4$ & $70.0 \pm 5.4$ \\
\hline Significance & $*$ & $*$ & $*$ & $*$ & $*$ & $*$ & $*$ \\
\hline
\end{tabular}

Values are means \pm standard errors of 5 plants.

NS: not significant, *: significant at $5 \%$ level by t-test

Table 3 Lutein concentration and total polyphenol concentration in leaf and petiole of 'Suioh' grown in the PSC system and the DFT system from May 18 to June $1,2006$.

\begin{tabular}{lcccc}
\hline \hline \multirow{2}{*}{ Cultivation system } & \multicolumn{2}{c}{ Lutein $\left(\mathrm{mg} 100 \mathrm{~g}^{-1} \mathrm{FW}\right)$} & \multicolumn{2}{c}{ Polyphenol $\left(\mathrm{mg} 100 \mathrm{~g}^{-1} \mathrm{FW}\right)$} \\
\cline { 2 - 5 } & Leaf & Petiole & Leaf & Petiole \\
\hline PSC & $6.67 \pm 0.70$ & $0.15 \pm 0.03$ & $503.89 \pm 42.33$ & $61.91 \pm 7.25$ \\
DFT & $4.84 \pm 0.30$ & $0.09 \pm 0.01$ & $486.59 \pm 49.00$ & $50.06 \pm 5.95$ \\
Significance & $*$ & $\mathrm{NS}$ & $\mathrm{NS}$ & $\mathrm{NS}$ \\
\hline
\end{tabular}

Values are means \pm standard errors of 5 plants. NS: not significant, *: significant at $5 \%$ level by t-test 
Table 4 Yields, number of leaves, leaf area, main stem length, number of lateral stems, and sum of lateral stem length of 'Suioh' grown in the PSC system and the DFT system from September 28 to October 12, 2006. Difference in the average root media temperature during cultivation between the PSC and DFT systems was decreased to $0.4{ }^{\circ} \mathrm{C}$ by controlling the nutrient solution temperature in the DFT system.

\begin{tabular}{lccccccc}
\hline \hline \multirow{2}{*}{$\begin{array}{c}\text { Cultivation } \\
\text { system }\end{array}$} & \multicolumn{2}{c}{ Yields $\left(\mathrm{g}\right.$ plant $\left.{ }^{-1}\right)$} & $\begin{array}{c}\text { No. of leaves } \\
\text { per plant }\end{array}$ & $\begin{array}{c}\text { Leaf area } \\
\left(\mathrm{cm}^{2} \text { leaf }\right.\end{array}$ 青) & $\begin{array}{c}\text { Main stem } \\
\text { length }(\mathrm{cm})\end{array}$ & $\begin{array}{c}\text { No. of lateral } \\
\text { stems per plant }\end{array}$ & $\begin{array}{c}\text { Sum of lateral } \\
\text { stem length }(\mathrm{cm})\end{array}$ \\
\hline PSC & $16.8 \pm 1.6$ & $9.1 \pm 0.6$ & $12.0 \pm 1.3$ & $78.2 \pm 4.8$ & $23.6 \pm 0.9$ & $1.0 \pm 1.0$ & $0.9 \pm 0.9$ \\
DFT & $32.3 \pm 4.4$ & $20.2 \pm 1.7$ & $28.6 \pm 2.1$ & $108.4 \pm 6.1$ & $38.0 \pm 2.5$ & $8.2 \pm 0.7$ & $24.4 \pm 6.4$ \\
Significance & $*$ & $*$ & $*$ & $*$ & $*$ & $*$ & $*$ \\
\hline
\end{tabular}

Values are means \pm standard errors of 5 plants.

NS: not significant, *: significant at $5 \%$ level by t-test

Table 5 Lutein concentration and total polyphenol concentration in leaf and petiole of 'Suioh' grown in the PSC system and the DFT system from September 28 to October 12, 2006. Difference in the average root media temperature during cultivation between the PSC and DFT systems was decreased to $0.4{ }^{\circ} \mathrm{C}$ by controlling the nutrient solution temperature in the DFT system.

\begin{tabular}{lcccc}
\hline \hline \multirow{2}{*}{ Cultivation system } & \multicolumn{2}{c}{ Lutein $\left(\mathrm{mg}^{\left.100 \mathrm{~g}^{-1} \mathrm{FW}\right)}\right.$} & \multicolumn{2}{c}{ Polyphenol $\left(\mathrm{mg} 100 \mathrm{~g}^{-1} \mathrm{FW}\right)$} \\
\cline { 2 - 5 } & Leaf & Petiole & Leaf & Petiole \\
\hline PSC & $6.60 \pm 0.38$ & $0.26 \pm 0.03$ & $551.93 \pm 29.79$ & $39.00 \pm 5.30$ \\
DFT & $5.65 \pm 0.87$ & $0.23 \pm 0.04$ & $494.47 \pm 24.91$ & $32.75 \pm 2.32$ \\
Significance & NS & NS & NS & NS \\
\hline
\end{tabular}

Values are means \pm standard errors of 5 plants.

NS: not significant, by t-test

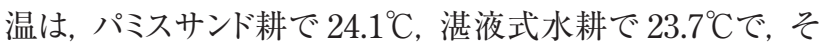

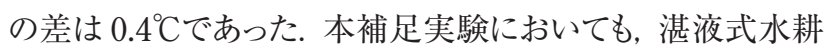
ではパミスサンド耕の 2 倍近い収量が得られ, 葉数, 葉面積, 主茎長, 側枝長, および側枝数すべてが湛液式水耕で高い 值を示した (Table 4). このことから, 夏作で認められた栽培 方式間の収量の違いは, 培地温の違いのみに起因するもの ではないことが示唆された. 本補足実験での収量は夏作より も低下していたが, これは日射量の少なさが原因の一つと考 えられる. 葉身のルテイン含量は固形培地耕で高い值を示し たが有意差は認められず, 葉身の総ポリフェノール含量にも 有意な差は認められなかった (Table 5).

\section{(3)冬作での比較}

地域気象観測所福岡地点で冬作の実験期間中 (2006 年 12 月 22 日〜 2007 年 1 月 12 日 ) の日照時間の累計は 79 時 間, 全天日射量の累計は $163.1 \mathrm{MJ} \mathrm{m}^{-2}$ であった. 日照時間 の累計は夏作とほぼ同じであったが, 日射量の累計は夏作の およそ 3 分の 2 であった. 冬期の栽培実験では, 両栽培方 式において葉柄の基部に花芽が形成されており, 目視で確認 された 1 個体当たりの花芽数は, パミスサンド耕で 10 個, 湛 液式水耕で 13 個であった. サツマイモは短日植物であるが, 同じ条件のファイトトロンガラス室で栽培した“ナルトキントキ’や ‘コガネセンガン’ では, 過去 10 年の間冬期に花芽の形成 は認められなかったので, ‘すいおう’ は日長感受性が比較的
高い品種と推察される.

Table 6 に冬作での各栽培方式における可食部収量, 葉 数, 葉面積, 主菱長, 側枝長, および側枝数を示す. 可食 部収量については葉身収量のみで有意な差が認められ, 湛 液式水耕でパミスサンド耕の約 1.2 倍の収量が得られた. 葉 数, 葉面積, 主茎長, 側枝長, および側枝数は, すべて湛 液式水耕で高い值を示し, 葉数および側枝長で有意な差が 認められた. 湛液式水耕では, 冬作においても夏作と同様に パミスサンド耕よりも分枝が盛んであり, これがより高い収量を もたらしたと考えられる. 機能性成分含量については, ルテイ ン, ポリフェノールともに両栽培方式において同等の值を示し た (Table 7).

以上のように, 冬作においても, 湛液式水耕で高い葉身収 量が得られた. しかし, 夏作での葉身収量と比較すると, 冬 作では栽培期間が 7 日間長く夏作の 1.5 倍であったにもかか わらず, パミスサンド耕では冬作の葉身収量は夏作の 1.2 倍, 湛液式水耕では 0.7 倍で, 特に湛液式水耕での冬作収量が 低く抑えられた. 冬作での収量の低下は, 栽培期間中の全天 日射量の累計が夏作よりも少なかったことから, 日照不足が原 因の一つと考えられる. また, 冬期短日下で生殖成長相に入 ったために地上部の生育が抑えられた可能性もある. しかし, 湛液式水耕での顕著な収量低下の原因を, 本実験結果から 推測することは難しい. 夏作, 冬作ともに湛液式水耕で高い 
Table 6 Yields, number of leaves, leaf area, main stem length, number of lateral stems, and sum of lateral stem length of 'Suioh' grown in the PSC system and the DFT system from December 22, 2006 to January 12, 2007.

\begin{tabular}{|c|c|c|c|c|c|c|c|}
\hline \multirow{2}{*}{ Cultivation system } & \multicolumn{2}{|c|}{ Yields $\left(\mathrm{g} \mathrm{plant}^{-1}\right)$} & \multirow{2}{*}{$\begin{array}{c}\text { No. of leaves } \\
\text { per plant }\end{array}$} & \multirow{2}{*}{$\begin{array}{l}\text { Leaf area } \\
\left(\mathrm{cm}^{2} l e f^{-1}\right)\end{array}$} & \multirow{2}{*}{$\begin{array}{l}\text { Main stem } \\
\text { length }(\mathrm{cm})\end{array}$} & \multirow{2}{*}{$\begin{array}{l}\text { No. of lateral } \\
\text { stems per plant }\end{array}$} & \multirow{2}{*}{$\begin{array}{c}\text { Sum of lateral } \\
\text { stem length }(\mathrm{cm})\end{array}$} \\
\hline & Leaf & Petiole & & & & & \\
\hline PSC & $32.8 \pm 1.6$ & $21.9 \pm 1.1$ & $22.2 \pm 1.3$ & $108.0 \pm 1.6$ & $47.8 \pm 1.7$ & $3.6 \pm 0.7$ & $8.2 \pm 2.3$ \\
\hline DFT & $39.8 \pm 2.3$ & $23.6 \pm 2.6$ & $31.0 \pm 3.1$ & $110.8 \pm 4.2$ & $47.0 \pm 3.4$ & $6.4 \pm 1.0$ & $21.2 \pm 1.6$ \\
\hline Significance & $*$ & NS & $*$ & NS & NS & NS & $*$ \\
\hline
\end{tabular}

Values are means \pm standard errors of 5 plants.

NS: not significant, *: significant at $5 \%$ level by t-test

Table 7 Lutein concentration and total polyphenol concentration in leaf and petiole of 'Suioh' grown in the PSC system and the DFT system from December 22, 2006 to January 12, 2007.

\begin{tabular}{ccccc}
\hline \hline \multirow{2}{*}{$\begin{array}{c}\text { Cultivation } \\
\text { system }\end{array}$} & \multicolumn{2}{c}{$\begin{array}{c}\text { Lutein } \\
\left(\mathrm{mg} 100 \mathrm{~g}^{-1} \mathrm{FW}\right)\end{array}$} & \multicolumn{2}{c}{$\begin{array}{c}\text { Polyphenol } \\
\left(\mathrm{mg} 100 \mathrm{~g}^{-1} \mathrm{FW}\right)\end{array}$} \\
\cline { 2 - 5 } & Leaf & Petiole & Leaf & Petiole \\
\hline PSC & $5.26 \pm 0.23$ & $0.15 \pm 0.02$ & $535.72 \pm 44.21$ & $20.53 \pm 2.46$ \\
DFT & $5.01 \pm 0.49$ & $0.15 \pm 0.02$ & $514.27 \pm 41.41$ & $17.44 \pm 1.40$ \\
Significance & $\mathrm{NS}$ & $\mathrm{NS}$ & $\mathrm{NS}$ & $\mathrm{NS}$ \\
\hline
\end{tabular}

Values are means \pm standard errors of 5 plants.

NS: not significant, by t-test

収量が得られたことから, ‘すいおう’の茎葉生産には湛液式 水耕がより適すると考えられるが, 本方式を採用するには葉 身のルテイン含量を高める栽培上の工夫が必要であることが 示唆された. な㧍, 本研究では, 栽培期間が夏作で 2 週間, 冬作で 3 週間と短かったため地下部には塊根の形成が認め られなかった. サツマイモは水中では塊根が形成されないこと が知られており 5, 10,16)，長期間の栽培においては, 湛液式水 耕では塊根が形成されず, パミスサンド耕では塊根が形成さ れると予想される. 塊根形成の有無が地上部の生育に影響 し，それを通して収量や品質に影響を与える可能性があるた め, このことに関しても調查が必要と考えられる.

\section{2.栽培条件が品質に及ぼす影響}

Fig. 2 に異なる培養液濃度下での葉身収量と葉身の機能 性成分含量を示す. 2 倍濃度区では対照区と比較して葉身 収量が $50 \%$ 低下した. 葉身のルテインおよびポリフェノール の含量は，両区ともほぼ同值であった．養分供給と機能性 成分含量との関わりについては, Bushman' s tea (Athrixia phylicoides L.) では窒素の施肥料を増やすと葉のポリフエノー ル含量が増大すること ${ }^{3)}$, チャでは窒素とかリウムをともに多く 施肥すると葉のポリフェノール含量が高〈なること ${ }^{17)}$, リンゴ, パセリでは窒素の施肥量を増やすと葉のルテイン含量が増大 すること ${ }^{4)}$ などが報告されている. ‘すいおう’の栽培において は，培養液濃度を 2 倍にしても機能性成分含量には影響が 認められず逆に減収したことから，他の作物で効果が認めら れたように, 窒素供給量のみを増やす等の培養液組成の調 整の効果を検証する必要があると考えられる.

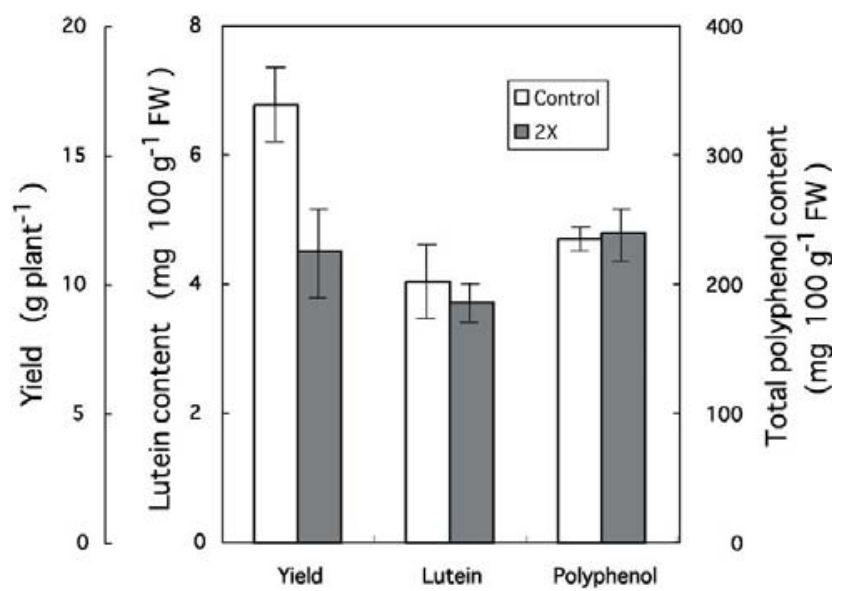

Fig. 2 Leaf yield, lutein concentration and total polyphenol concentration in leaves of 'Suioh' grown under two different conditions of nutrient solution concentration, control and doublestrength concentration. Electric conductance of the nutrient solution was $1.2 \mathrm{mS} \mathrm{cm}^{-1}$ in control and $2.4 \mathrm{mS} \mathrm{cm}^{-1}$ in the double-strength concentration treatment. Values are means \pm standard errors of 4 plants.

Fig. 3 に異なる光強度下での葉身収量と葉身の機能性成 分含量を示す. 収量および機能性成分含量ともに両区間に 有意な差は認められなかったが, いずれの值も強光区で高い 值を示す傾向にあった. 明確な光量増加の効果を得るには, 処理区間により大きな光強度差を設定する必要があると考え られる. 対照区と比較すると強光区で約 1.4 倍の葉身収量を 示した. ルテインについては, 強光区が対照区よりも 40\%高い 


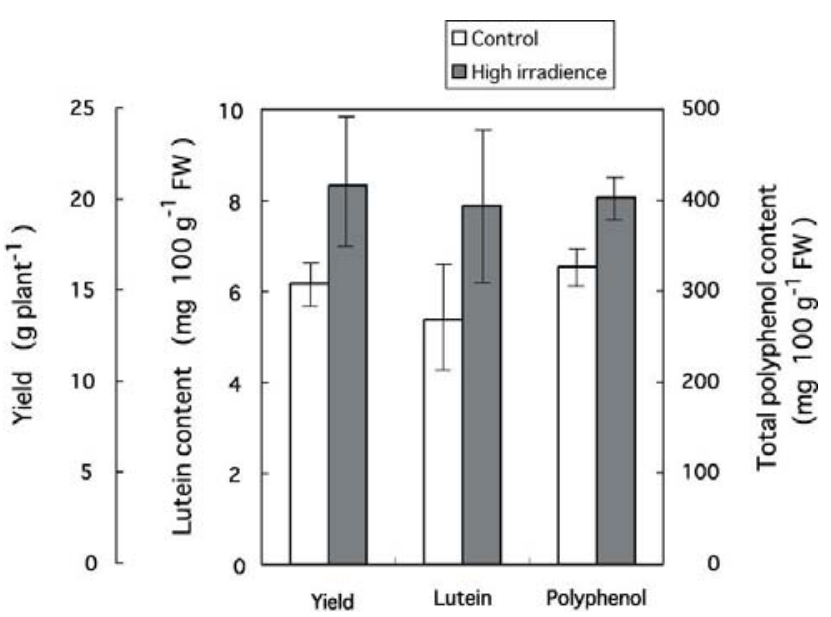

Fig. 3 Leaf yield, lutein concentration and total polyphenol concentration in leaves of 'Suioh' grown under two different conditions of light intensity of the shoot environment, control and relatively high irradiance. PPFD was $200 \mu \mathrm{mol} \mathrm{m}{ }^{-2} \mathrm{~s}^{-1}$ in control and $280 \mu \mathrm{mol} \mathrm{m} \mathrm{m}^{-2} \mathrm{~s}^{-1}$ in the high irradiance treatment. Values are means \pm standard errors of 4 plants.

葉身含量を示し, クレマチス, オオムギ, ダイズでの報告 ${ }^{1,2)}$ と 同様に光量が増加したことで葉中のルテインも増加したと考え られる. ポリフェノールについては, 強光区が対照区よりも 20 \%高い葉身含量を示し, ‘エレガントサマー’などの茥葉利用サ ツマイモ品種についての Islam ら ${ }^{6)}$ の報告と同様の結果が 得られており, 光量が増加したことでポリフェノール類の生成 が増加したと考えられる.

以上のように, より強い光強度下でルテインおよびポリフェ ノールの含量が増加する傾向が認められ, ‘すいおう’ の機 能性成分含量は, 栽培時の光条件によって影響されることが 示唆された. 実際の生産現場に本結果を反映させるには,さ らに詳細な光強度の影響調査が必要であり, 加えて補光や その光質が収量や品質に及ぼす影響をも明らかにする必要 がある.

\section{摘 要}

本研究では, 新規野菜として, また機能性食品として期待 されるサツマイモ品種 ‘すいおう’ の養液栽培方式の検討を 行った. その結果, 高い収量を得るには夏作, 冬作ともに湛 液式水耕が適することが明らかになった. しかし, 夏作におい ては, 機能性成分であるルテインの葉身含量がパミスサンド耕 よりも劣るため, 湛液式水耕において機能性成分含量を高め るための栽培技術の開発が必要であることが示唆された. ま た, 培養液濃度および光強度条件が ‘すいおう’の葉身機 能性成分含量に影響を与え得るかを調査したところ, 培養液
濃度の影響は認められなかったが, 光強度が機能性成分含 量および葉身収量に影響することが示唆された。 ‘すいおう’の 生産性向上のためには, 栽培環境が収量や品質に及ぼす影 響のより詳細な調査が求められる.

\section{謝辞}

本研究を実施するにあたり，“すいおう’の種著を分譲いた だた独立行政法人 農業・食品産業技術総合研究機構 九州沖縄農業研究センター サツマイモ育種研究チームに記 して謝意を表す。

\section{引用文献}

1) Barry P, Young JA, Britton G. Accumulation of pigment during the greening of etiolated seedlings of Hordeum vulagare L. J. Exp. Bot. 42(235) : 229-234. 1991.

2) Bungard RA, McNeil D, Morton. JD. Effects of nitrogen on the photosynthetic apparatus of Clematis vitalba grown at several irradiances. Aust. J. Plant Physiol 24(2) : 205-214. 1997.

3) Cartelat A, Cerovic ZG, Goulas Y, Meyer S, Lelarge C, Prioul JL, Barbottin A, Jeuffroy MH, Gate P, Agati G, Moya I. Optically assessed contents of leaf polyphenolics and chlorophyll as indicators of nitrogen deficiency in wheat (Triticum aestivum L.). Field Crops Res. 91(1) : 35-49 2005.

4) Cheng L. Xanthophyll cycle pool size and composition in relation to the nitrogen content of apple leaves. $\mathrm{J}$. Exp. Bot. 54(381) : 385-393. 2003.

5) Eguchi T, Yoshida S. A cultivation method to ensure tuberous root formation in sweetpotatoes (Ipomoea batatas (L.) Lam.). Environ. Control in Biol. 42(4) : 259-266. 2004.

6) Islam S, Yoshimoto $\mathrm{M}$, Ishiguro $\mathrm{K}$, Okuno $\mathrm{S}$, Yamakawa O. Effect of artificial shading and temperature on radical scavenging activity and polyphenolic composition in sweetpotato (Ipomoea batatas L.) leaves. J. Amer. Soc. Hort. Sci. 128(2) : 182-187. 2003.

7) Ishiguro K, Toyama J, Islam S, Yoshimoto M, Kumagai T. Suioh. A new sweetpotato cultivar for utilization in vegetable greens. Acta Hort. 637: 339-345. 2004.

8) Ishiguro K, Yoshimoto M. Lutein content of sweetpotato leaves. Sweetpotato Res. Front 20:4. 2006.

9) 伊東秀夫. 甘著の塊根形成に関する研究 (第 2 報 ) 水耕栽培に依る甘藷塊根形成. 農業及び園芸 21(1)： 13-14. 1946.

10）春日井新一郎. 甘藷の水耕法について. 日本作物学会 紀事 $7: 12.1935$. 
11) Lefsrud MG, Kopsell DA, Auge RM, Both AJ. Biomass production and pigment accumulation in kale grown under increasing photoperiods. Hortscience 41(3) : 603-606. 2006.

12) 前田智雄, 角田英男, 大島千周, 前川健次郎, 鈴木 卓, 大澤勝次. 補光装置によるアブラナ科スプラウトのポ リフェノール含量および抗酸化能の増大. 植物環境工 学 18(1) : 35-41. 2006.

13) 満田幸恵, 新本洋志, 小堀真珠子, 津志田藤二郎. 高速クロマトグラフィーによる野菜のカロテノイドおよびク ロロフイルの同時分析. 日本食品化学工学会誌 49(7): 500-506. 2002.

14) 水野 智. ルテインその機能と重要性. 食品工業 46 : 32-38. 2003.
15) Ruhl K, Hartmann W, Stosser R. Polyphenol content in Prunus domestica as in fluenced by different factors. Gartenbauwissenschaft 57( 6 ) : 260-266. 1992.

16) 上和田 勉. サツマイモの養液栽培に関する研究. 生 物環境調節 28(4) : 135-140.1990.

17) Venkatesan S, Ganapathy MNK. Nitrate reductase activity in tea as influenced by various levels of nitrogen and potassium fertilizers. Communications in Soil Science and Plant Analysis 35(9\& 10): 1283-1291. 2004.

18) 吉元 誠. サツマイモ茥葉に含まれるポリフェノール類の 薬理作用. 食品工業 48:69-74. 2005. 